\title{
Transcatheter Arterial Chemoembolization Therapy for Patients With Unresectable Hepatocellular Carcinoma
}

\author{
Kavous Firouznia ${ }^{1}$; Hossein Ghanaati ${ }^{1, *}$; Seyed Moayed Alavian ${ }^{2}$; Payam Azadeh $^{3}$; Mohsen \\ Nasiri Toosi ${ }^{4}$; Arya Haj Mirzaian ${ }^{1}$; Safa Najafi ${ }^{5}$; Madjid Shakiba ${ }^{1}$; Amir Hossein Jalali ${ }^{1}$

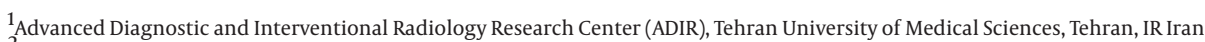 \\ ${ }^{2}$ Baqiyatallah Research Center for Gastroenterology and Liver Diseases, Baqiyatallah University of Medical Sciences, Tehran, IR Iran \\ ${ }^{3}$ Department of Radiation Oncology, Shahid Beheshti University of Medical Sciences, Tehran, IR Iran \\ ${ }_{5}^{4}$ Internal Medicine Department, Imam-Khomeini Hospital, Tehran University of Medical Sciences (TUMS), Tehran, IR Iran \\ ${ }^{5}$ Tehran University of Medical Sciences, Tehran, IR Iran \\ ${ }^{*}$ Corresponding Author: Hossein Ghanaati, Advanced Diagnostic and Interventional Radiology Research Center (ADIR), Tehran University of Medical Sciences, Tehran, IR Iran. Tel: \\ +98-2166581516, Fax: +98-2166581578, E-mail: ghanaati@yahoo.com
}

Received: December 3, 2014; Accepted: December 17, 2014

\begin{abstract}
Background: Although transcatheter arterial chemoembolization (TACE) has been widely used as a palliative treatment for unresectable hepatocellular carcinoma (HCC), its actual efficacy and prognostic usefulness have not been clarified in past studies.

Objectives: The aim of the study is to investigate the efficacy, complications, and prognostic factors of the TACE in unresectable HCC patients.

Patients and Methods: Thirty-two patients with unresectable HCC were treated with TACE. The procedure was performed with a combination of Lipiodol, doxorubicin, and cytomycin followed by gelatin-sponge particles embolization. CT-scan imaging and liver function tests (AST, ALT, ALP, BIL, and PT) were performed before and after the TACE. All patients were followed-up for 6-months.

Results: Of all patients, 1 and 11 patients respectively, exhibited a complete response (CR)and a partial response (PR) (response rate, CR+PR, 44\%). Data have shown that tumor size, number of lesions and number of involved segments are significantly reduced after the TACE performance $(\mathrm{P}<0.05)$. No significant clinical adverse effect was observed in patients after the intervention. Also, liver function tests including AST, ALT, ALP, BIL, and PT did not significantly differ before and after the intervention (P>0.05). The 6-month cumulative survival rates of the 32 patients were $78.1 \%$, respectively. Univariate analysis showed that survival correlated significantly with the following factors: tumor size; $\geq 8 \mathrm{~cm}$ versus $<8 \mathrm{~cm}(\mathrm{P}<0.010)$, serum ALP level; $<300$ versus $\geq 300(\mathrm{P}<0.043)$, and number of liver involved segments; $<$ 2 versus $\geq 2(\mathrm{P}<0.020)$.

Conclusions: We showed that in treatment of patients with unresectable hepatocellular carcinoma, TACE significantly improved the disease and the overall survival rate. Also, we introduce the tumor size, serum ALP level, and number of liver involved segments as prognostic factors of the procedure. Finally, TACE can be recommended as the initial treatment for unresectable HCC patients.
\end{abstract}

Keywords:Hepatocellular Carcinoma; Treatment; Lipiodol

\section{Background}

Hepatocellular carcinoma (HCC) is one of the most common malignancies especially in Asian countries (1). Besides the prevalence, the incidence of HCC has also elevated recently (2). Increase in the risk factors that contribute to the development of HCC is responsible for the rising incidence of the disease (3). Chronic hepatitis B virus (HBV) infection is one of the most prevalent risk factors for development of HCC, especially in Iran (4). It has been suggested that over 35\% of Iranians have been exposed to the HBV and about $3 \%$ are chronic carriers (5). Also, past studies showed that $80 \%$ of HCC patients are positive for at least one of the HBV markers in Iran (6). The HCC prognosis is very poor and it has been considered as the fourth cause of death related to cancer worldwide (7). The only curative treatment for patients with HCC seems liver-resection surgery and transplantation. However, because of tumor ex- tension and hepatic dysfunction, less than $20 \%$ of patients are suitable for these treatments (8). Therefore, a number of alternative treatments, including trans-catheter arterial chemo-embolization (TACE), alcohol injection, and radiofrequency tumor ablation, have been suggested informer studies (9). Today, TACE is used as a gold-standard palliative treatment of unresctable HCC (10). Past studies have suggested contra/indication lists for this procedure (11). In this method, the tumor-feeding artery is catheterized; then, an emulsion is injected through the catheter. The emulsion consists of an oily contrast media that accumulates selectively in tumor, such as Lipiodol, and a chemotherapeutic agent, either Doxorubicin, Cisplatin, or other drugs (12). It was shown that TACE improved the survival of HCC patients who were not appropriate for resection/transplantation (13). However, these results have been confirmed by

Copyright (C) 2014, Kowsar Corp. This is an open-access article distributed under the terms of the Creative Commons Attribution-NonCommercial 4.0 International License (http://creativecommons.org/licenses/by-nc/4.0/) which permits copy and redistribute the material just in noncommercial usages, provided the original work is properly cited. 
few controlled trials (14). Despite the wide use of TACE as a palliative treatment, its real indication, efficacy, and survival effect remains controversial.

\section{Objectives}

In the current study, all patients treated at our institution with TACE for unresectable HCC are reviewed. This study was accomplished to determine the efficacy and complications of the procedure in an Iranian population for the first time. Also, we tried to investigate the prognostic factors following TACE, to conclude which patients can benefit from this treatment.

\section{Patients and Methods}

\subsection{Patients}

From April 2010 to March 2013, 32 patients were treated with TACE at radiology Department of our universityaffiliated hospital for HCC. The patients consisted of 21 men and 11 women, with a mean age $52.9 \pm 14$.2years (range, 16-76 years). HCC in patients was diagnosed by distinctive findings of clinical data, CT signs, and elevated afetoprotein (AFP). The diagnosis was also confirmed histologically by CT-guided fine-needle biopsy in all patients $(15,16) .21 .9 \%$ of patients had been treated previously with chemotherapy and $9.4 \%$ had received surgery before the TACE performance. The other patients $(68.7 \%)$ were treated with TACE alone.

\subsection{Pre-Intervention Study}

After diagnosis, the serum counts of ALT (alanine aminoteransferase), AST (aspartate aminotransferase), ALP (alkaline phosphatase), PT (prothrombin time), Cr (creatinine) and BIL (bilirubin) were measured in all patients. The Child-Pugh classification was used in patients who suffered from cirrhosis due to HCC. Also, following factors were evaluated on the basis of radiographic findings including ultrasonography and CT-scan: The size of the biggest tumor lesion, number of lesions, vascularity of the tumor, location (based on the liver segments), number of involved segments of liver, presence of portal vein invasion, pattern of CT-scan, and extra-hepatic metastasis. Patient characteristics assessed just before the initial TACE is depicted in Table 1. TACE was designed for all patients who were not contraindicated for the procedure. The relative contraindications of TACE included allergic reaction, recent TACE performance in 30 days, liver dysfunction (PT > 15, BIL > 3, AST and ALT higher than 5 times as much as normal), $\mathrm{Cr}>1.5$, progressive heart disease, uncontrolled blood pressure, severe infection, uncontrolled diabetes, extra-hepatic metastasis, pregnancy, lactation, main portal vein thrombosis (PVT), uncontrolled electrolyte dysregulation, hepatic encephalopathy, and Child-Pugh score $>11$. According to the documented laboratory findings and pre-intervention study, unsuitable patients whom were contraindicated for the procedure were excluded from the further parts of the study.

\subsection{Trans-Catheter Arterial Chemo-Embolization}

Patients were fasted for one night (17). Then, TACE was performed as reported previously (18). The tumor-feeding arteries were selectively catheterized by DSA-angiography. Thereafter, the emulsion was injected through the coaxial 3F or F (Simmons clova) micro- catheter. The injected emulsion was composed of 10-30 mL of iodized oil (Lipiodol Ultra-Fluide; Andre` Guerbet Laboratories, AulnaySous-Bois, France) and 40-100 mg of doxorubicin and cytomycine (Adriamycin; Adria, Dublin, $\mathrm{OH}$ ). The dose of

\begin{tabular}{|c|c|}
\hline & Data \\
\hline Age, $y$ & $25.9 \pm 14.2(16-76)$ \\
\hline \multicolumn{2}{|l|}{ Gender } \\
\hline Male & $21(65.6)$ \\
\hline Female & $11(34.4)$ \\
\hline \multicolumn{2}{|l|}{ First symptom } \\
\hline Mass & $27(84.4)$ \\
\hline Pain & $5(15.6)$ \\
\hline Past chemotherapy & $7(21.9)$ \\
\hline Past surgery & $3(9.4)$ \\
\hline Tumor size, cm & $7.3 \pm 2.9$ \\
\hline \multicolumn{2}{|l|}{ Tumor Number } \\
\hline 1 & $22(68.8)$ \\
\hline 2 & $2(6.3)$ \\
\hline 3 & $2(6.3)$ \\
\hline 4 & $2(6.3)$ \\
\hline 5 & $1(3.1)$ \\
\hline 6 & $3(9.4)$ \\
\hline \multicolumn{2}{|c|}{ Number of involved segment } \\
\hline 1 & $12(37.5)$ \\
\hline 2 & $12(37.5)$ \\
\hline 3 & $4(12.5)$ \\
\hline 4 & $3(9.4)$ \\
\hline 5 & $1(3.1)$ \\
\hline \multicolumn{2}{|l|}{ Tumor vascularity } \\
\hline Нyро & $29(90.6)$ \\
\hline Hyper & $3(9.4)$ \\
\hline \multicolumn{2}{|l|}{ Tumor location } \\
\hline Right & $21(65.6)$ \\
\hline Left & $7(21.9)$ \\
\hline Both & $4(12.5)$ \\
\hline AST & $47.00 \pm 27.657$ \\
\hline ALT & $77.25 \pm 32.960$ \\
\hline ALP & $458.64 \pm 354.223$ \\
\hline BIL & $0.6471 \pm 0.53579$ \\
\hline PT & $13.490 \pm 1.4611$ \\
\hline $\begin{array}{l}\text { a Abbreviations: AST, } \\
\text { aminoteransferase; ALP, } \\
\text { prothrombin time. } \\
\text { b Data are presented as Me }\end{array}$ & $\begin{array}{l}\text { transferase; ALT, a } \\
\text { latase; BIL, bilirubi } \\
\text {. }\end{array}$ \\
\hline
\end{tabular}


Firouznia Ket al.

doxorubicin/ cytomycine was determined based on the tumors size and number. This was followed by embolization using gelatin-sponge particles. When TACE was accomplished, vital signs were routinely monitored every $2 \mathrm{~h}$ in the first $6 \mathrm{~h}$ after procedure. Hematological, liver and renal function was monitored on the next day and 1 week after TACE. Triphasic CT-scan was performed 1 month after the procedure to evaluate the number and size of all tumors. The need for another TACE and the outcome of the procedure were determined based on these imaging findings. Also, liver function tests including AST, ALT, ALP, PT, and BIL test were performed in all patients 6 months after TACE.

\subsection{Follow-up, Analyses of TACE Efficacy, Compli- cations, Survival and Prognostic Factors}

Changes in tumor were assessed using CT, before and 1 month after the initial therapy. The tumor size, number, vascularity, location, pattern and portal involvement were evaluated by this imaging study. The maximal tumor size was calculated by multiplying the two longest crossed diameters of the tumor on the pre and post intervention $\mathrm{CT}$ images. According to the WHO criteria, the outcome of TACE has been defined as follows: 1) complete remission (CR); disappearance of all tumors without new lesion emergence. 2) Partial remission (PR); minimum 50\% decrease in tumor size. 3) Minor response (MR); a reduction of 25 to $50 \%$ in tumor size. 4 ) No change (NC); a reduction less than $25 \%$. 5) Progressing disease (PD), minimum 25\% increase in tumor size or appearance of new lesion. CR and PR were considered effective. Two days after treatment, the serum counts of ALT, AST, ALP, PT, and BIL were measured in all patients. Any changes in the liver function tests, disruption in patient's vital signs, renal and hematologic dysfunction, and other clinical abnormalities were considered as a procedure complication. Survival of all patients was evaluated during the 6 months after TACE. A total of 14 variables likely to influence surveillance were selected (i.e. age, gender, tumor size, tumors number, tumor vascularity, tumor location, number of liver involved segments, history of previous surgery/chemotherapy, serum total BIL/ALT/AST/ALP/PT). Preliminary analysis of the prognostic significance of different cut-off values for each variable was performed, and the cut-off value that best discriminated between 6-month survivors and those surviving less than 6 month was used in the univariate and multivariate. Comparisons of factors between before and after TACE conditions were performed by Paired t-test and uni/ multi-variate analyses were used to evaluate the possible prognostic factors. All analyses were performed in the SPSS package software (version 21) and Graph-pad prism software (version 6). Statistical differences were evaluated to be significant when the P value was less than 0.05 .

\section{Results}

\subsection{Tumor Response}

The tumor response in all patients is shown in Table 2. Complete response (CR) and partial response (PR) were observed in $44 \%$ of patients. Data showed that the average size of the biggest lesion before the intervention was about $7.3 \pm 2.9 \mathrm{~cm}$ (Table 1). However, after the TACE performance, average tumor size had become $4.8 \pm 2.8 \mathrm{~cm}$ ( $\mathrm{P}<$ $0.0001)$. TACE significantly decreased the tumor size with the reduction percentage of $37.6 \pm 19.2 \%$. $\left({ }^{\mathrm{a}} \mathrm{P}<0.0001\right.$, Figure $1 \mathrm{~A}$ ). On the other hand, results showed that the TACE also lowered the number of tumor lesions and involved segments. Paired t-test analyses showed that there was a significant difference in the numbers of tumors $\left({ }^{b} \mathrm{P}<\right.$ 0.0319 , Figure 1 B)/ involved segments ( ${ }^{\mathrm{C}} \mathrm{P}<0.0171$, Figure 1 C) between pre and post conditions.

Table 2. Tumor Response to Transcatheter Arterial Chemo-Embolization in 32 Hepato Cellular Carcinoma Patients a,b

\begin{tabular}{|c|c|c|c|c|c|c|}
\hline & CR & PR & MR & NC & SD & Total \\
\hline Number of response (percentage) & $1(3)$ & $11(41)$ & $13(34)$ & $7(22)$ & $0(0)$ & $32(100)$ \\
\hline
\end{tabular}

A

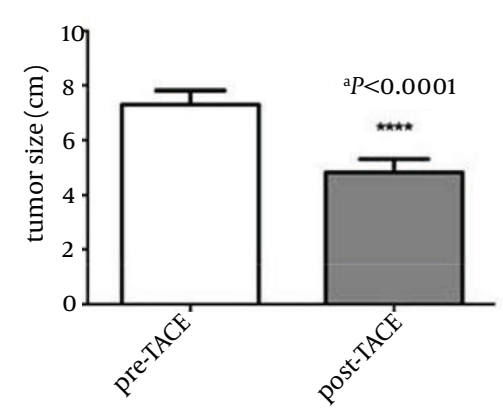

B

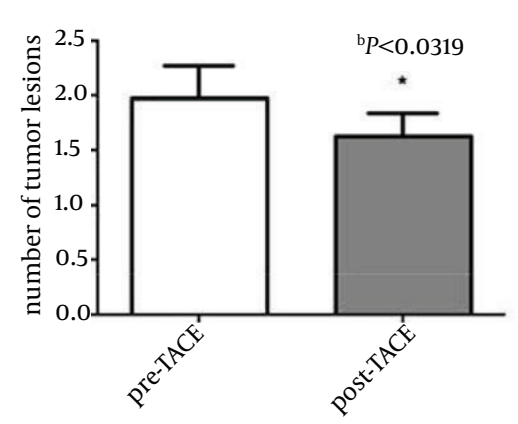

C

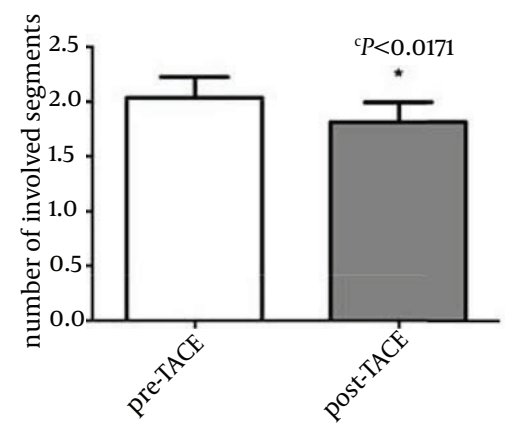

Figure 1. Effect of Transcatheter Arterial Chemo-Embolization on Tumor size, Numbers and Involved Segments in Hepatocellular Carcinoma Patients 
Firouznia Ket al.

Table 3. Univariate Analysis of Pre-Treatment Host Variables a,b

\begin{tabular}{|c|c|c|c|}
\hline & $\begin{array}{c}\text { Number of } \\
\text { Patients }\end{array}$ & $\begin{array}{l}\text { Number of } \\
\text { survivors }\end{array}$ & P Value \\
\hline Age & & & 0.35 \\
\hline$<60, \mathrm{y}$ & $21(32)$ & $17(21)$ & \\
\hline$\geq 60, y$ & $11(32)$ & $3(11)$ & \\
\hline Gender & & & 0.595 \\
\hline Male & $20(32)$ & $15(20)$ & \\
\hline Female & $12(32)$ & $10(12)$ & \\
\hline AST & & & 0.774 \\
\hline$<100$ & $12(16)$ & $8(12)$ & \\
\hline$\geq 100$ & $4(16)$ & $3(4)$ & \\
\hline ALT & & & 0.411 \\
\hline$<50$ & $9(16)$ & $7(9)$ & \\
\hline$\geq 50$ & $7(16)$ & $4(7)$ & \\
\hline ALP & & & $0.043^{*}$ \\
\hline$<300$ & $6(14)$ & $6(6)$ & \\
\hline$\geq 300$ & $8(14)$ & $5(8)$ & \\
\hline BIL & & & 0.630 \\
\hline$<1$ & $9(14)$ & $6(9)$ & \\
\hline$\geq 1$ & $5(14)$ & $4(5)$ & \\
\hline PT & & & 0.682 \\
\hline$<13$ & $16(32)$ & $14(16)$ & \\
\hline$\geq 13$ & $16(32)$ & $12(16)$ & \\
\hline $\begin{array}{l}\text { Past chemo- } \\
\text { therapy }\end{array}$ & & & 0.956 \\
\hline No & $11(18)$ & $11(11)$ & \\
\hline Yes & $7(18)$ & $6(7)$ & \\
\hline Past surgery & & & 0.669 \\
\hline No & $23(26)$ & $18(23)$ & \\
\hline Yes & $3(26)$ & $2(3)$ & \\
\hline Tumor size & & & $0.010^{* *}$ \\
\hline$<8, \mathrm{~cm}$ & $18(32)$ & $17(18)$ & \\
\hline$\geq 8, \mathrm{~cm}$ & $14(32)$ & $8(14)$ & \\
\hline Tumor number & & & 0.813 \\
\hline$\leq 2$ & $24(32)$ & $19(24)$ & \\
\hline$>2$ & $8(32)$ & $7(8)$ & \\
\hline Tumor pattern & & & 0.336 \\
\hline Hypo-vascular & $30(32)$ & $24(30)$ & \\
\hline Hyper-vascular & $2(32)$ & $1(2)$ & \\
\hline Tumor location & & & 0.561 \\
\hline One lobe & $27(32)$ & $20(27)$ & \\
\hline Both lobes & $5(32)$ & $5(5)$ & \\
\hline $\begin{array}{l}\text { Involved seg- } \\
\text { ment }\end{array}$ & & & $0.020^{* *}$ \\
\hline$<2$ & $12(32)$ & $12(12)$ & \\
\hline$\geq 2$ & $20(32)$ & $13(20)$ & \\
\hline \multicolumn{4}{|c|}{$\begin{array}{l}\text { a Abbreviations: AST, aspartate aminotransferase; ALT, alanine } \\
\text { aminoteransferase; ALP, alkaline phosphatase; BIL, bilirubin; PT, } \\
\text { prothrombin time. } \\
\text { b Data are presented No.(\%). }\end{array}$} \\
\hline
\end{tabular}

\subsection{Complications}

The most frequent side effects of the TACE procedure were fever, headache, abdominal pain, nausea, and liver dysfunction. None of the patients showed serious clinical complications and side effects (Data not shown). In laboratory findings, four patients showed elevated level of aminotransferase (12.5\%), alkaline phosphate level was increased in three patients (9.4\%), bilirubin amount was elevated in five patients (15.6\%), and prothrombin time was increased in nine patients (28.1\%). However, Paired ttest did not show any significant differences in the serum level of AST, ALT, ALP, BIL and PT in patients before and after the procedure $(\mathrm{P}>0.05)$.

\subsection{Survival Rate and Prognostic Factors}

All patients were followed for 6 months after the intervention. There was no patient, which was lost to follow. During the six months follow-up, 7 of 32 patients (21.9\%) died. So, the survival rate in the six months after the TACE was calculated $78.1 \%$. We investigated the relationship between survival after the TACE induction and various clinicopathological variables. Univariate analysis revealed 14 possible prognostic factors affecting the survival:(i.e., age, gender, tumor size, tumors number, tumor vascularity, tumor location, number of liver involved segments, history of previous surgery/chemotherapy, serum total BIL/ALT/AST/ALP/PT) (Table 3). Univariate analysis showed that survival was correlated significantly with the following factors: 1 ) Tumor size; $\geq 8 \mathrm{~cm}$ versus $<8 \mathrm{~cm}$ (P $<0.010), 2$ ) Serum ALP level; $<300$ versus $\geq 300$ ( $\mathrm{P}<$ $0.043), 3$ ) Number of liver involved segments; $<2$ versus $\geq 2(\mathrm{P}<0.020)$. However, other factors such as age, gender, tumor numbers, tumor vascularity, history of previous surgery/chemotherapy, liver function test showed no prognostic significance. On multivariate analysis, the tumor size $(\mathrm{P}<0.012)$ and serum ALP level $(\mathrm{P}<0.049)$ were independent predictors of 6-month survival. Unlike the univariate results, number of liver involved segments was not considered as a significant independent predictor in multivariate analysis $(\mathrm{P}>0.295)$ (Data not shown in Figures/Tables).

\section{Discussion}

Hepatocellular carcinoma (HCC) is one of the most common malignancies especially in Asian countries (1). Surgical resection and liver transplantation have been considered the only treatment for long-term control of the disease. However, most patients are not suitable candidates for the surgery at the time of diagnosis, either due to tumor extension or inadequate hepatic function $(7,19)$. Nonsurgical modalities, including TACE, can be used selectively and repeatedly for patients with unresectable HCC $(9,20,21)$. However, the real indications and outcome of this palliative therapy are not clearly defined (22). Therefore, there is a need for more studies to indicate the real efficacy, complications and indications of 
Firouznia Ket al.

this treatment. The efficacy of TACE can be assessed in different ways; for example by imaging response, biologic response, and quality of life. In this study, imaging findings were used to determine the efficacy of the procedure. One week after TACE performance, patients were evaluated by the abdominal CT-scan. The tumor size, number of lesions, and the number of involved segments were measured and compared with the last findings in the pre-intervention imaging study. Paired t-test revealed that the TACE significantly reduced the tumor size $(\mathrm{P}<$ $0.0001)$, number of lesions $(\mathrm{P}<0.0319)$, and the number of involved segments $(\mathrm{P}<0.0171)$ in HCC patients. These results are in line with the past studies which showed that TACE may provide some tumor response (23). On the other hand, the efficacy of the TACE was also reported based on the WHO criteria, which have been discussed earlier. In this criteria CR and PR are considered as the effective response. Based on the meta-analysis of the past studies, the TACE efficacy has been reported with a median of 38\% (range 3-86\%) $(24,25)$. Complete response (CR) and partial response (PR) was reported with a median value of 0 (range0-35\%) and 30\% (3-62\%) in the past experiments which used Lipiodol, doxorubicin, cytomycine and the same procedure as the current study (26-28). In another review article the efficacy of the procedure was reported $28-39 \%$ (29). In our study, the objective response rate was $41 \%$ for PR and 3\% for CR. Our results are not significantly different from the last studies. Finally, we have shown that the overall efficacy of TACE in the current study is about $44 \%$. Post-embolization syndrome occurs in lots of patients who undergo TACE. Typical signs and symptoms include abdominal discomfort, pain, nausea, fatigue, and fever, which may last for few days (30). Appropriate management of these symptoms is not a big challenge, but some major complications may occur after the TACE procedure. It is important to recognize the development of a liver abscess, ischemic cholecystitis, and septicemia as early as possible. Liver failure and hepatorenal syndrome are two life-threatening complications of TACE. Also, Chan et al. have shown that the TACE induced an elevation in the serum bilirubin level (31). In this study we monitored all patients for 48 hours after the TACE performance. Monitoring has shown that there was no evidence of severe complications and problems. Also, the liver function tests (AST, ALT, and PT), bilirubin and ALP were measured in all patients, next day and oneweek after the TACE induction. Paired t-test analysis has shown that there was no significant difference in the levels of AST, ALT, ALP, PT and bilirubin between before and after the intervention conditions. Thus, it can be concluded that TACE performance had no adverse effects both in clinical and laboratory findings. The evaluation of a palliative treatment, such as TACE, needs comparison with a standard treatment as a positive control group (such as surgery and transplantation) or with a negative control group (absence of treatment), in terms of survival and tumor response in a randomized and controlled study.
However, such an approach raises important ethical problems, because a number of patients would be left untreated. Therefore, the real effect of TACE on patient survival rate and tumor response is not clear. There are lots of studies, which have suggested that TACE can improve the survival rate of the HCC patients (32). Based on these articles, the effect of TACE on the survival rate is depended on the method, drug, patient selection criteria, and other factors. Llovet et al. have used the chemo-embolization including doxorubicin and lipiodol for HCC patients. The 1-, 2- and 3-year survival rates for chemembolization were 82,63 and $29 \%$. Although usage of the same drugs as our study, the patient selection criteria in this study was different for the current manuscript (33). Kawai et al. evaluated the effect of intra-arterial doxorubicin and lipiodol as a component of TACE. The 1-, 2- and 3-year survival values for the procedure was 74.4, 51.3 and 33.6\% (34). All taken together, some studies have showed the beneficial effect of TACE on the short-term survival rate. However, there are few reports which have illustrated the longterm survival of the procedure (35). The 5-years survival rate of HCC patients after TACE performance has been determined 1 to $8 \%$ by the past studies $(35,36)$. Our study showed that the overall 6 month survival rates of the 32 patients who underwent TACE were $78.1 \%$. Past reports have shown that the survival rate of the HCC patients without any cancer therapy is about $31-63 \%$ for one-year (37). In another report, the median survival of unresectable HCC patients without any treatment has been reported 1.6 months (7). Our findings have suggested that the TACE performance can improve the survival rate. However, there was no control group to compare these results with. The analyzed variables that correlated with patient survival in the univariate analysis are tumor size ( $\geq 8 \mathrm{~cm}$ versus $<8 \mathrm{~cm}$ ), serum ALP level ( $<300$ versus $\geq$ 300 ), and number of liver involved segments ( $<2$ versus $\geq 2$ ). The prognostic value of tumor size has also been suggested by some authors. The studies of Ikeda et al.(38) and Mondazzi et al. (39) reported that tumor size had a prognostic value. In another study, Child score, level of alpha-fetoprotein, tumor size, tumor grade, and PVT have been proposed as the prognostic factor of the TACE (40). However, to our knowledge, there is no study to show the prognostic role of serum ALP level, and number of liver involved segments in TACE survival rate. Thus, we showed for the first time that the ALP level and number of liver involved segments could be independent prognostic factors of the TACE. However, because of our inadequate patient numbers, more studies should be done to evaluate the possible role of these factors in predicting the TACE survival rate. Finally, there are lots of studies, which have determined the prognostic factors of this procedure. However, there are many controversies in the past reports. Therefore, there is need for more studies to indicate the actual prognostic factors of the TACE and to show which patients will benefit from TACE. In this study we tried to show the efficacy, complications, survival rate, 
and possible prognostic factors of the TACE procedure. We showed that the TACE significantly affected the size and number of liver lesions without any significant adverse effects. Our findings, like the past reports, introduced the TACE as a proper palliative treatment for unresectable HCC patients. However, there is a need for more studies to evaluate the different aspects of this procedure. The real indications and prognostic factors of this method are not fully cleared. And there is no evidence to show which patients can benefit from TACE. Finally, we mentioned to the limitations of this study. Number of patients and the duration of follow-up, 6 month, are low I in this article. Also, the exact surveillance of the each patient was not investigated. Also, it was no control group and that was not possible to compare the results with the control untreated group.

\section{Authors' Contributions}

Kavous Firouznia and Hossein Ghanaati contributed equally to this work; Payam Azadeh, Seyed Moayed Alavian, and Mohsen Nasiri Toosi designed the research; Kavous Firouznia and Hossein Ghanaati performed the research; Arya Haj Mirzaian, Safa Najafi, and Madjid Shakiba analyzed the data; and Arya Haj-Mirzaian and Amir Hossein Jalali wrote the paper.

\section{References}

1. Cook GC. Hepatocellular carcinoma: one of the world's most common malignancies. QJ Med.1985;57(223):705-8.

2. El-Serag HB, Mason AC. Rising incidence of hepatocellular carcinoma in the United States. N Engl J Med.1999;340(10):745-50.

3. Parkin DM, Bray F, Ferlay J, Pisani P. Global cancer statistics, 2002. CA Cancer J Clin. 2005;55(2):74-108.

4. Ataei B, Tayeri K, Kassaian N, Farajzadegan Z, Babak A. Hepatitis B and $\mathrm{C}$ among patients infected with human immunodeficiency virus in Isfahan, Iran: seroprevalence and associated factors. Hepat Mon. 2010;10(3):188-92.

5. Alavian SM, Fallahian F, Lankarani KB. The changing epidemiology of viral hepatitis B in Iran. J Gastrointestin Liver Dis. 2007;16(4):403-6.

6. Ali F, Iman F, Babak E, Parivash S, Parisa F, Yaser G, et al. screening for hepatocellular carcinoma in chronic carriers of hepatitis $B$ and C in markazi province, iran. Hepat Mon. 2007(3):149-52.

7. Okuda K, Ohtsuki T, Obata H, Tomimatsu M, Okazaki N, Hasegawa $\mathrm{H}$, et al. Natural history of hepatocellular carcinoma and prognosis in relation to treatment. Study of 850 patients. Cancer 1985;56(4):918-28.

8. Hajiani E, Masjedizadeh R, Hashemi J, Azmi M, Rajabi T. Risk factors for hepatocellular carcinoma in Southern Iran. Saudi Med J 2005;26(6):974-7.

9. Lehnert T, Herfarth C. Chemoembolization for hepatocellular carcinoma. What, when, and for whom? Ann Surg.1996;224(1):1-3.

10. Maleux G, van Malenstein H, Vandecaveye V, Heye S, Vaninbroukx J, Nevens F, et al. Transcatheter chemoembolization of unresectable hepatocellular carcinoma: current knowledge and future directions. Dig Dis. 2009;27(2):157-63.

11. Chung YH, Song IH, Song BC, Lee GC, Koh MS, Yoon HK, et al. Combined therapy consisting of intraarterial cisplatin infusion and systemic interferon-alpha for hepatocellular carcinoma patients with major portal vein thrombosis or distant metastasis. Cancer 2000;88(9):1986-91.

12. Ando E, Yamashita F, Tanaka M, Tanikawa K. A novel chemotherapy for advanced hepatocellular carcinoma with tumor thrombosis of the main trunk of the portal vein. Cancer.1997;79(10):1890-6.
13. Jaeger HJ, Mehring UM, Castaneda F, Hasse F, Blumhardt G, Loehlein D, et al. Sequential transarterial chemoembolization for unresectable advanced hepatocellular carcinoma. Cardiovasc Intervent Radiol.1996;19(6):388-96.

14. A comparison of lipiodol chemoembolization and conservative treatment for unresectable hepatocellular carcinoma. Groupe d'Etude et de Traitement du Carcinome Hepatocellulaire. NEngl J Med.1995;332(19):1256-61.

15. Cakmakci E, Caliskan KC, Tabakci ON, Tahtabasi M, Karpat Z. Percutaneous liver biopsies guided with ultrasonography: a case series. Iran J Radiol. 2013;10(3):182-4.

16. Ghanaati H, Alavian SM, Jafarian A, Ebrahimi Daryani N, NassiriToosi M, Jalali AH, et al. Imaging and Imaging-Guided Interventions in the Diagnosis and Management of Hepatocellular Carcinoma (HCC)-Review of Evidence. Iran J Radiol. 2012;9(4):167-77.

17. Ghanaati H, Firouznia K, Jalali AH, Shakiba M. How to Start Interventional Radiology. Iran Red Crescent Med J. 2013;15(12).

18. Valls C, Pamies JJ, Sancho C, Benasco C, Figueras J, Dominguez J, et al. Computed tomography after Lipiodol chemoembolization in hepatocellular carcinoma. Eur Radiol. 1994;4(3):238-42.

19. Caglayan B, Salepci B, Dogusoy I, Fidan A, Sener Comert S, Kiral N et al. The role of convex probe endobronchial ultrasound guided transbronchial needle aspiration in the diagnosis of malignant mediastinal and hilar lymph nodes. Iran J Radiol. 2012;9(4):183-9.

20. Ghanaati H, Firouznia K, Jalali AH, Shakiba M. Advances of interventional radiology in treatment of hepatobiliary diseases in Iran. Hepat Mon. 2011;11(7):507-10.

21. Rajesh R, Dalip DS, Anupam J, Jaisiram A. Effectiveness of puncture-aspiration-injection-reaspiration in the treatment of hepatic hydatid cysts. Iran J Radiol. 2013;10(2):68-73.

22. Ngan H, Lai CL, Fan ST, Lai EC, Yuen WK, Tso WK. Transcatheter arterial chemoembolization in inoperable hepatocellular carcinoma: four-year follow-up. J Vasc Interv Radiol. 1996;7(3):419-25.

23. Gadaleta CD, Ranieri G. Trans-arterial chemoembolization as a therapy for liver tumours: New clinical developments and suggestions for combination with angiogenesis inhibitors. Crit Rev Oncol Hematol. 2011;80(1):40-53.

24. Marelli L, Stigliano R, Triantos C, Senzolo M, Cholongitas E, Davies N, et al. Transarterial therapy for hepatocellular carcinoma: which technique is more effective? A systematic review of cohort and randomized studies. Cardiovasc Intervent Radiol. 2007;30(1):6-25.

25. Vogl TJ, Naguib NN, Nour-Eldin NE, Rao P, Emami AH, Zangos S, et al. Review on transarterial chemoembolization in hepatocellular carcinoma: palliative, combined, neoadjuvant, bridging, and symptomatic indications. Eur J Radiol. 2009;72(3):505-16.

26. Bruix J, Sala M, Llovet JM. Chemoembolization for hepatocellular carcinoma. Gastroenterology. 2004;127(5 Suppl 1):S179-88.

27. Solomon B, Soulen MC, Baum RA, Haskal ZJ, Shlansky-Goldberg $\mathrm{RD}$, Cope C. Chemoembolization of hepatocellular carcinoma with cisplatin, doxorubicin, mitomycin-C, ethiodol, and polyvinyl alcohol: prospective evaluation of response and survival in a U.S. population. J Vasc Interv Radiol. 1999;10(6):793-8.

28. Georgiades CS, Hong K, D'Angelo M, Geschwind JF. Safety and efficacy of transarterial chemoembolization in patients with unresectable hepatocellular carcinoma and portal vein thrombosis. $J$ Vasc Interv Radiol. 2005;16(12):1653-9.

29. Liapi E, Geschwind JF. Intra-arterial therapies for hepatocellular carcinoma: where do we stand? Ann Surg Oncol. 2010;17(5):1234-46.

30. Goin JE, Roberts CA, Dancey JE, Sickles CJ, Leung DA, Soulen MC Comparison of post-embolization syndrome in the treatment of patients with unresectable hepatocellular carcinoma: transcatheter arterial chemo-embolization versus yttrium-90 glass microspheres. World J Nucl Med. 2004;3(1):49-56.

31. Chan AO, Yuen MF, Hui CK, Tso WK, Lai CL. A prospective study regarding the complications of transcatheter intraarterial lipiodol chemoembolization in patients with hepatocellular carcinoma. Cancer. 2002;94(6):1747-52.

32. Llovet JM, Bruix J. Systematic review of randomized trials for unresectable hepatocellular carcinoma: Chemoembolization improves survival. Hepatology. 2003;37(2):429-42.

33. Llovet JM, Real MI, Montana X, Planas R, Coll S, Aponte J, et al. Ar- 
terial embolisation or chemoembolisation versus symptomatic treatment in patients with unresectable hepatocellular carcinoma: a randomised controlled trial. Lancet. 2002;359(9319):1734-9.

34. Kawai S, Okamura J, Ogawa M, Ohashi Y, Tani M, Inoue J, et al. Prospective and randomized clinical trial for the treatment of hepatocellular carcinoma--a comparison of lipiodol-transcatheter arterial embolization with and without adriamycin (first cooperative study). The Cooperative Study Group for Liver Cancer Treatment of Japan. Cancer Chemother Pharmacol. 1992;31 Suppl:S1-6.

35. O'Suilleabhain CB, Poon RT, Yong JL, Ooi GC, Tso WK, Fan ST. Factors predictive of 5-year survival after transarterial chemoembolization for inoperable hepatocellular carcinoma. Br J Surg. 2003;90(3):325-31.

36. Yamada R, Kishi K, Sato M, Sonomura T, Nishida N, Tanaka K, et al Transcatheter arterial chemoembolization (TACE) in the treatment of unresectable liver cancer. World J Surg.1995;19(6):795-800.
37. Reidy DL, Schwartz JD. Therapy for unresectable hepatocellular carcinoma: review of the randomized clinical trials-I: hepatic arterial embolization and embolization-based therapies in unresectable hepatocellular carcinoma. Anticancer Drugs. 2004;15(5):427-37.

38. Ikeda M, Okada S, Yamamoto S, Sato T, Ueno H, Okusaka T, et al. Prognostic factors in patients with hepatocellular carcinoma treated by transcatheter arterial embolization. Jpn J Clin Oncol. 2002;32(11):455-60.

39. Mondazzi L, Bottelli R, Brambilla G, Rampoldi A, Rezakovic I, Zavaglia C, et al. Transarterial oily chemoembolization for the treatment of hepatocellular carcinoma: a multivariate analysis of prognostic factors. Hepatology. 1994;19(5):1115-23.

40. Llado L, Virgili J, Figueras J, Valls C, Dominguez J, Rafecas A, et al. A prognostic index of the survival of patients with unresectable hepatocellular carcinoma after transcatheter arterial chemoembolization. Cancer. 2000;88(1):50-7. 